\title{
Rasgo falciforme e infarto esplénico: una entidad no ajena en población antioqueña
}

Sickle trait and splenic infarction, a non-foreign entity in Antioquia population

Pablo Arango-Guerra', Natalia Banoy-Restrepo², Federico Rodríguez-Vega ${ }^{3}$

Fecha correspondencia: Recibido: enero 25 de 2020. Revisado: julio 17 de 2020. Aceptado: agosto 11 de 2020.

Forma de citar: Arango-Guerra P, Banoy-Restrepo N. Rodríguez-Vega F. Rasgo falciforme e infarto esplénico: una entidad no ajena en población antioqueña. Rev CES Med 2020; 34(2): 136-143.

Open access

(C) Derecho de autor

Licencia creative commons

Ética de publicaciones

Revisión por pares

Gestión por Open Journal System

DOl: http://dx.doi.org/10.21615/

cesmedicina.34.2.5

ISSN 0120-8705

e-ISSN 2215-9177
Comparte

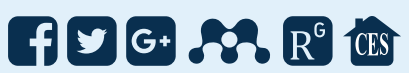

\section{Resumen}

Generalmente, los pacientes con rasgo falciforme sufren pocas manifestaciones del espectro de la anemia de células falciformes. El infarto esplénico es raro, pero es una complicación documentada del rasgo falciforme y, usualmente, se presenta en condiciones de disminución de la presión parcial de oxígeno, como ocurre en grandes alturas. Se presenta el caso de un joven sin antecedentes, quien presentó dolor súbito en hipocondrio izquierdo luego de viaje a zona de gran altura y en quien se documentó infarto esplénico y posteriormente se confirmó como etiología del cuadro, rasgo falciforme mediante electroforesis de hemoglobina. La mayoría de los pacientes desconocen su rasgo falciforme, lo que hace desafiante su enfoque, retrasa el diagnóstico y resulta en manejos inadecuados que pueden aumentar la extensión del infarto esplénico y requerir finalmente esplenectomía.

Palabras clave: Rasgo falciforme; Enfermedad de la hemoglobina SC; Infarto esplénico; Hipoxia.

\begin{abstract}
Generally, patients with sickle cell trait have few manifestations of the sickle cell spectrum. Splenic infarction is rare, but is a documented complication of sickle cell trait and usually occurs under conditions of decreased partial pressure of oxygen, such as at high altitudes. We present the case of a young man with no previous history who presented sudden pain in the left hypochondrium after traveling to a high-altitude area. Splenic infarction was documented and sickle cell trait was later confirmed with hemoglobin electrophoresis as the etiology of the condition. Most patients remain ignorant of their sickle cell trait, which makes their approach challenging, delays diagnosis, and results in inappropriate management that may increase the extent of splenic infarction and eventually require splenectomy.
\end{abstract}

Keywords: Sickle cell trait; Hemoglobin SC Disease; Splenic infarct; Hypoxia.

\section{Introducción}

Los pacientes con rasgo falciforme son usualmente asintomáticos, no cursan con anemia y no tienen otros rasgos característicos hematológicos que se expresan en la anemia de células falciformes. Aun así pueden presentarse 


\section{Sobre los autores:}

1. Médico general, Clínica CES

2. Estudiante de Medicina, Universidad CES.

3. Médico internista, Clínica CES.
Dado que las principales causas de infarto esplénico son la tromboembolia y la infección, con frecuencia se subestima la posibilidad de rasgo falciforme como etiología subyacente. complicaciones específicas que tornan esta condición no del todo benigna, tales como embolia pulmonar, proteinuria, enfermedad renal crónica y rabdomiólisis (1). El infarto esplénico es otra de las complicaciones descritas y se precipita con la exposición a grandes alturas (2).

Aunque el rasgo falciforme es común en algunas poblaciones, la documentación de infarto esplénico secundario a exposición a grandes alturas se ha restringido a reportes de caso o pequeñas series de casos, posiblemente por subdiagnóstico o subregistro. Dado que las principales causas de infarto esplénico son la tromboembolia y la infección, con frecuencia se subestima la posibilidad de rasgo falciforme como etiología subyacente. La mayoría de los casos son de curso benigno, sin embargo, la esplenectomía continúa siendo realizada debido a diagnósticos imprecisos y tardíos $(2,3)$.

Se presenta el caso de un paciente que cursó con infarto esplénico provocado por exposición a zona de gran altura y sin previo conocimiento de rasgo falciforme ni antecedente familiar de anemia de células falciformes. El objetivo de este artículo es dar a conocer las bases fisiopatológicas y manifestaciones clínicas de esta enfermedad, ya que puede presentarse en distintas poblaciones del país y de otras regiones, lo que la hace de interés para el médico general o especialista.

\section{Caso clínico}

Un hombre mestizo de 24 años residente en Medellín (1495 msnm), previamente sano, experimentó dolor súbito e incapacitante en hipocondrio izquierdo irradiado a hombro izquierdo. El dolor se presentó al ascender al corregimiento de Santa Elena (2200 msnm). Adicionalmente, presentó diaforesis y tres episodios eméticos y de diarrea que se autolimitaron. Negó episodios similares previos. Consultó inicialmente a centro de baja complejidad donde se manejó como gastroenteritis viral, pero ante persistencia del dolor abdominal intenso focalizado y mala apariencia general se trasladó a centro de mayor complejidad.

Allí ingresó con discreta ictericia, sin palidez mucocutánea, frecuencia cardíaca de 95 por minuto, frecuencia respiratoria de 18 por minuto, presión arterial de $110 / 70 \mathrm{~mm} / \mathrm{Hg}$ y afebril. En la evaluación abdominal reportaba intenso dolor en hipocondrio izquierdo, así como esplenomegalia, sin claros signos de irritación peritoneal.

Como hallazgos significativos en los exámenes paraclínicos se obtuvo deshidrogenasa láctica (LDH) elevada, trombocitopenia leve y discreta hiperbilirrubinemia indirecta, sin anemia importante ni hallazgos de hemólisis intravascular, esquistocitos o esferocitos (cuadro 1).

La ecografía abdominal reveló discreta esplenomegalia con alteración de su ecogenicidad que sugería infartos subcapsulares esplénicos. Estos hallazgos se confirmaron con tomografía (figuras 1 y 2). Se descartó endocarditis infecciosa, trombosis venosa esplénica, microangiopatía trombótica, cardioembolia, trombofilia heredada, neoplasia y malignidad hematológica. 
Cuadro 1. Exámenes de laboratorio

La ecografía abdominal reveló discreta esplenomegalia con alteración de su ecogenicidad que sugería infartos subcapsulares esplénicos. Estos hallazgos se confirmaron con tomografía.

\begin{tabular}{|c|c|c|c|c|c|}
\hline Parámetros & Dia 1 & Dia 3 & 2 meses & 4 meses & Valor Referencia \\
\hline & $\begin{array}{l}\text { Leucocitos } \\
6700 / \mathrm{mL}\end{array}$ & $\begin{array}{l}\text { Leucocitos } \\
6490 / \mathrm{mL}\end{array}$ & $\begin{array}{l}\text { Leucocitos } \\
6590 / \mathrm{mL}\end{array}$ & $\begin{array}{l}\text { Leucocitos } \\
6210 / \mathrm{mL}\end{array}$ & $4500-11000 / \mathrm{mL}$ \\
\hline & $\begin{array}{l}\text { Neutrófilos } \\
3900 / \mathrm{mL}\end{array}$ & $\begin{array}{l}\text { Neutrófilos } \\
1620 / \mathrm{mL}\end{array}$ & $\begin{array}{l}\text { Neutrófilos } \\
5280 / \mathrm{mL}\end{array}$ & $\begin{array}{l}\text { Neutrófilos } \\
4740 / \mathrm{mL}\end{array}$ & $1400-6500 / \mathrm{mL}$ \\
\hline \multirow[t]{3}{*}{ Hemograma } & $\begin{array}{l}\text { Hemoglobina } \\
12,3 \mathrm{~g} / \mathrm{dL}\end{array}$ & $\begin{array}{l}\text { Hemoglobina } \\
12,1 \mathrm{~g} / \mathrm{dL}\end{array}$ & $\begin{array}{l}\text { Hemoglobina } \\
14,1 \mathrm{~g} / \mathrm{dL}\end{array}$ & $\begin{array}{c}\text { Hemoglobina } \\
15,6 \mathrm{~g} / \mathrm{dL}\end{array}$ & $13,5-18 \mathrm{~g} / \mathrm{dL}$ \\
\hline & $\begin{array}{c}\text { Hematocrito } \\
37,4 \%\end{array}$ & $\begin{array}{c}\text { Hematocrito } \\
34 \%\end{array}$ & $\begin{array}{c}\text { Hematocrito } \\
40,1 \%\end{array}$ & $\begin{array}{c}\text { Hematocrito } \\
44,2 \%\end{array}$ & $40-54 \%$ \\
\hline & $\begin{array}{l}\text { Plaquetas } \\
125000 / \mathrm{mL}\end{array}$ & $\begin{array}{c}\text { Plaquetas } \\
187000 / \mathrm{mL}\end{array}$ & $\begin{array}{l}\text { Plaquetas } \\
170000 / \mathrm{mL}\end{array}$ & $\begin{array}{c}\text { Plaquetas } \\
233000 / \mathrm{mL}\end{array}$ & $150000-450000$ \\
\hline $\begin{array}{l}\text { Extendido } \\
\text { de sangre } \\
\text { periférica }\end{array}$ & Normal & Normal & Normal & Normal & Normal \\
\hline $\begin{array}{l}\text { Fosfatasa } \\
\text { alcalina }\end{array}$ & $96.7 \mathrm{U} / \mathrm{L}$ & $112 \mathrm{U} / \mathrm{L}$ & & & $40-129 \mathrm{U} / \mathrm{L}$ \\
\hline LDH & $557 \mathrm{U} / \mathrm{L}$ & \multicolumn{2}{|c|}{$433 \mathrm{U} / \mathrm{L}$} & $210 \mathrm{U} / \mathrm{L}$ & $135-225 \mathrm{U} / \mathrm{L}$ \\
\hline $\begin{array}{l}\text { Bilirrubina } \\
\text { total }\end{array}$ & $2,26 \mathrm{mg} / \mathrm{dL}$ & $0,86 \mathrm{mg} / \mathrm{dL}$ & $1,10 \mathrm{mg} / \mathrm{dL}$ & & $0,00-1,00 \mathrm{mg} / \mathrm{dl}$ \\
\hline $\begin{array}{l}\text { Bilirrubina } \\
\text { directa }\end{array}$ & $0,63 \mathrm{mg} / \mathrm{dL}$ & $0,32 \mathrm{mg} / \mathrm{dL}$ & $0,62 \mathrm{mg} / \mathrm{dL}$ & & $0,00-0,2 \mathrm{mg} / \mathrm{dl}$ \\
\hline $\begin{array}{l}\text { Bilirrubina } \\
\text { indirecta }\end{array}$ & $1,63 \mathrm{mg} / \mathrm{dL}$ & $0,54 \mathrm{mg} / \mathrm{dL}$ & $0,48 \mathrm{mg} / \mathrm{dL}$ & & $0,00-0,87 \mathrm{mg} / \mathrm{dl}$ \\
\hline Serología VIH & \multicolumn{4}{|c|}{ Negativo } & Negativo \\
\hline $\begin{array}{l}\text { Antígeno } \\
\text { superficie } \\
\text { hepatitis B }\end{array}$ & \multicolumn{4}{|c|}{ Negativo } & Negativo \\
\hline $\begin{array}{l}\text { Hepatitis C } \\
\text { anticuerpos }\end{array}$ & \multicolumn{4}{|c|}{ Negativo } & Negativo \\
\hline
\end{tabular}
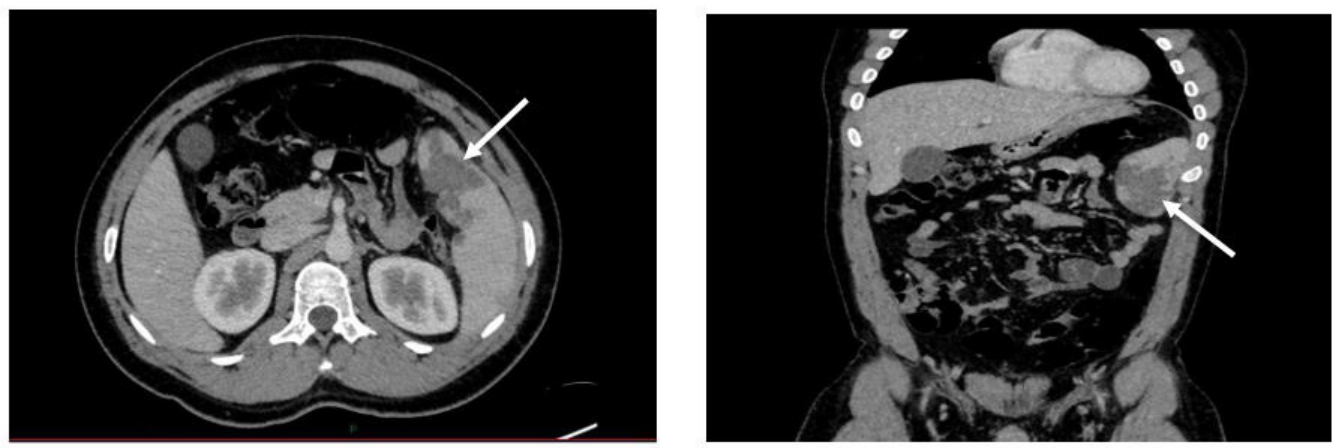

Figuras 1-2. Tomografía axial computarizada. La flecha blanca indica área que corresponde a infarto esplénico.

Posteriormente, y ante una clara asociación de la aparición de dolor con la exposición a zona de gran altura, se solicitó electroforesis de hemoglobina con técnica capilar, la cual reportó 39,3\% de hemoglobina S, 57,7 \% de hemoglobina A1 y $3 \%$ de hemoglobina $A 2$, compatible con patrón electroforético de rasgo falciforme y este como etiología del infarto esplénico. El paciente fue tratado con suplencia de oxígeno, hidratación endovenosa y modulación del dolor. Se logró respuesta clínica y paraclínica favorable. Fue dado de alta con analgesia e instrucciones para evitar viajes a sitios de alturas mayores a 2000 msnm, ejercicio extenuante, limitar condiciones que lo expusieran 
El rasgo falciforme está presente en uno de cada 12 afroamericanos y en aproximadamente 300 millones de personas en el mundo. En Colombia, se describen prevalencias variables, como $8,09 \%$ en la región andina, 2,4\% en Cali, 4,8 \% en Buenaventura y 3,53\% en Medellín. Aunque la mayoría de los casos han sido reportados en hombres, no se trata de una condición exclusiva del sexo masculino; tampoco de población de raza negra, pues hay una cantidad importante de caucásicos afectados, incluso sin ascendencia africana. a hipoxia y asegurar una adecuada hidratación. En meses posteriores se observó el paciente sin evidencia de nuevos eventos vaso-oclusivos u otras complicaciones y con exámenes de laboratorio sin anormalidades significativas.

\section{Discusión}

El rasgo falciforme es un desorden hematológico heterocigoto caracterizado por una mutación en uno de los alelos del gen de la hemoglobina $\mathrm{S}$ que es consecuencia de la sustitución aminoacídica y que altera la constitución de la beta globina. Normalmente, tiene comportamiento benigno, en contraste con la expresión homocigota conocida como anemia de células falciformes. Sin embargo, bajo ciertas condiciones específicas, puede tener manifestaciones clínicas significativas $(4,5)$.

Según datos del sistema de registro y vigilancia de hemoglobinopatías del Centro de Control de Enfermedades (CDC, por sus siglas en inglés), se estima que el rasgo falciforme está presente en uno de cada 12 afroamericanos y en aproximadamente 300 millones de personas en el mundo (6). En Colombia, se describen prevalencias variables, como 8,09 \% en la región andina, 2,4 \% en Cali, 4,8 \% en Buenaventura y 3,53 \% en Medellín (7-9).

La mayoría de los casos han sido reportados en hombres, pero no se trata de una condición exclusiva del sexo masculino; tampoco de población de raza negra, pues hay una cantidad importante de caucásicos afectados, incluso sin ascendencia africana con una razón incluso de 1.4:1 (10). Tanto paciente negros y caucásicos desconocían tener rasgo falciforme en $44 \%$ y 85 \% respectivamente en algunos reportes (11).

La hemoglobina normal se compone de dos subunidades de globina: alfa y beta. La hemoglobina S (HbS) es la consecuencia de una mutación del gen que codifica para la beta-globina y está dada por la sustitución de valina por glutamato en la posición 6, que produce un tetrámero de hemoglobina que aumenta la superficie hidrofóbica y disminuye su solubilidad cuando está desoxigenada. La polimerización de HbS desoxigenada resulta en distorsión estructural y pérdida de la capacidad de deformación del eritrocito que además se deshidrata y se torna más frágil. La frecuencia y magnitud de la polimerización dependerá del grado de desoxigenación y concentración de HbS. Dicho fenómeno puede culminar en crisis vaso-oclusivas que desencadenan trombosis, hemólisis e infartos, especialmente de lechos capilares del bazo, riñones, pulmones y sistema nervioso central $(12,13)$.

La anatomía vascular esplénica y condiciones fisiológicas de la médula renal hacen que sean lechos propicios para oclusión vascular bajo condiciones de hipoxia, como grandes alturas sobre el nivel del mar o ejercicio extenuante, lo que desencadena complicaciones renales como hematuria e hipostenuria. A nivel pulmonar puede desencadenar eventos tromboembólicos e infartos. La ruptura esplénica con indicación quirúrgica emergente es infrecuente (14).

Los primeros reportes de infarto esplénico se describieron en pacientes que habían viajado en aviones presurizados y no presurizados, lo cual ha soportado la hipótesis del cambio de la presión parcial de oxígeno que desencadena las manifestaciones clínicas $(15,16)$.

No está determinada con precisión la altitud en la cual se presenta polimerización de HbS, aunque según reportes de caso, se estima que varía entre 1117 y 5000 msnm (17,18). Aun así, en escenarios controlados se ha tratado de estimar el grado 
La presencia del rasgo falciforme se establece al encontrar tanto hemoglobina A ( $\mathrm{HbA})$ como HbS en la electroforesis de hemoglobina, con mayor porcentaje de $\mathrm{HbA}$ que de $\mathrm{HbS}$. de deformación reversible de los eritrocitos durante ejercicio extenuante en militares con rasgo falciforme, encontrando que alrededor de $1200 \mathrm{msnm}$ se logra un $2 \%$ de deformidad del total de hematíes en comparación a un 8,5 \% a 4000 msnm, y se deduce que no solo la hipoxia y las altas altitudes condicionan dicho fenómeno, sino también el grado deshidratación, temperatura e intensidad del esfuerzo físico $(5,19)$.

Debe tenerse en cuenta los diagnósticos diferenciales de infarto esplénico tales como malignidad hematológica, trombofilia heredada, eventos cardioembólicos, endocarditis infecciosa y trauma cerrado de abdomen, antes de pensar en rasgo falciforme como etiología (20).

La manifestación típica de infarto esplénico es el dolor abdominal agudo que inicia súbitamente luego de viajes a sitios de gran altitud, predomina en epigastrio e hipocondrio izquierdo y podría cursar incluso con características de abdomen agudo quirúrgico. Puede haber irritación subdiafragmática, dolor pleurítico y derrame pleural ipsilateral $(14,21)$.

En el caso reportado, el paciente desarrolló un cuadro similar a lo anteriormente descrito, lo que orientó la sospecha clínica después de haber descartado otras causas más frecuentes de infarto esplénico. Más que las características étnicas y demográficas, la sospecha diagnóstica debe enfocarse según el contexto clínico, ya que esta entidad no es exclusiva de pacientes de raza o ascendencia negra, y estas condiciones cada vez son más frecuentes dado el aumento de las corrientes migratorias. Si la circunstancia clínica y hallazgos paraclínicos lo sugieren esta condición debe tenerse dentro del diagnóstico diferencial $(10,22)$.

Puede encontrarse hiperbilirrubinemia indirecta, elevación de LDH, reticulocitosis y anemia como expresión de un proceso hemolítico y vaso-oclusivo, hallazgos presentes en el caso presentado $(14,21,23)$. En la mayoría de los casos reportados hay ausencia de drepanocitos en el extendido de sangre periférica del paciente con rasgo falciforme, explicado por un menor grado de severidad en la polimerización de hemoglobina en comparación con la expresión homocigota de la enfermedad. La deformación de los eritrocitos, cuando se presenta, generalmente es reversible pues al momento de la valoración clínica, ha cesado el desencadenante que condujo a la deformación de los hematíes $(3,5)$.

La presencia del rasgo falciforme se establece al encontrar tanto hemoglobina $\mathrm{A}(\mathrm{HbA})$ como $\mathrm{HbS}$ en la electroforesis de hemoglobina, con mayor porcentaje de $\mathrm{HbA}$ que de $\mathrm{HbS}$. Típicamente, los individuos afectados tienen valores de $\mathrm{HbA}$ entre $50 \%$ y $60 \%$ y HbS entre $35 \%$ y $40 \%(4,17,23)$. Existen pruebas rápidas utilizadas especialmente en zonas de bajos recursos económicos, pero que no superan la información brindada por la electroforesis de hemoglobina, por lo que en la actualidad se sugiere su realización para establecer con certeza la presencia del rasgo (4).

Usualmente, el manejo del infarto esplénico en contexto de anemia de células falciformes es la esplenectomía. Si se presenta en el escenario de rasgo falciforme, el manejo conservador ha demostrado ser efectivo y los pacientes responden sin complicaciones. Lo más importante es evitar condiciones de hipoxia, exposición a grandes alturas, ejercicio extenuante y precauciones al viajar. Solo en circunstancias puntuales como hemorragia, formación de abscesos, pseudoquistes o sepsis, se optará por abordaje quirúrgico (14). 
El manejo del infarto esplénico en contexto de anemia de células falciformes es la esplenectomía. Si se presenta en el escenario de rasgo falciforme, el manejo conservador ha demostrado ser efectivo y los pacientes responden sin complicaciones. Solo en circunstancias puntuales como hemorragia, formación de abscesos, pseudoquistes o sepsis, se optará por el abordaje quirúrgico.
En general, la salud y la expectativa de vida de las personas con rasgo falciforme no se ven afectadas, pero debe reconocerse que no es un estado del todo benigno.

Llama la atención que en muchos reportes de caso se han realizado laparotomías y laparoscopias exploratorias innecesarias, y es reiterativa la expresión de algunos autores diciendo que pudiesen haberse evitado dichos procedimientos con un buen interrogatorio y un apropiado umbral de sospecha. El desconocimiento de esta entidad y su presentación clínica es el principal obstáculo para el diagnóstico oportuno (2).

\section{Aplicaciones futuras}

En algunos países se han desarrollado programas de tamización neonatal para rasgo falciforme y asesoramiento genético con el fin de identificar de forma temprana y facilitar la institución de medidas. Aunque el rasgo falciforme tiene un curso benigno, se reconoce como un problema de salud pública por sus implicaciones en cuanto a salud sexual y reproductiva. Se han implementado programas de asesoramiento pre y post concepción para disminuir la prevalencia de anemia de células falciformes mediante fertilización in vitro (24).

\section{Conclusión}

El infarto esplénico secundario a rasgo falciforme debe sospecharse en pacientes que se presenten con dolor agudo en hipocondrio izquierdo posterior a exposición a moderadas o grandes alturas, no importa su etnia u origen. El reconocimiento de esta entidad evita estudios y procedimientos invasivos innecesarios que no mejorarán el pronóstico del paciente, ya que con solo buena hidratación y modulación del dolor es suficiente para un buen desenlace clínico.

\section{Aspectos éticos}

El reporte de este caso tuvo en cuenta las pautas CIOMS 2016 (25) y se contó con autorización del Comité de Investigación de la Clínica CES.

\section{Bibliografía}

1. Naik RP, Smith-Whitley K, Hassell KL, Umeh NI, Montalembert MD, Sahota P, et al. Clinical outcomes associated with sickle cell trait: A systematic review. Ann Intern Med. 2018;169(9):619-27.

2. Kumar R, Kapoor R, Singh J, Das S, Sharma A, Yanamandra U, et al. Splenic infarct on exposure to extreme high altitude in individuals with Sickle Trait: A Single-Center Experience. High Alt Med Biol. 2019;20(3):215-20.

3. Arora M, Bhatia J, Khanna V, Jaiswal P, Charan V. Splenic syndrome due to sickle Cell Trait amongst Indian soldiers serving in Kashmir. Med J Armed Forces India. 2008;64(2):123-6.

4. Xu JZ, Thein SL. The carrier state for sickle cell disease is not completely harmless. Haematologica. 2019;104(6):1106-11.

5. Tsaras G, Owusu-Ansah A, Boateng FO, Amoateng-Adjepong Y. Complications associated with sickle cell trait: a brief narrative review. Am J Med. 2009;122(6):507-12. 
6. CDC. Data \& Statistics on Sickle Cell Disease I CDC [Internet]. Centers for Disease Control and Prevention. 2016. Disponible en: https://www.cdc.gov/ncbddd/sicklecell/data.html

7. Romero-Sánchez C, Gómez Gutiérrez A, Duarte Y, Amazo C, Manosalva C, Chila M $L$, et al. Hemoglobin variants in Colombian patients referred to discard hemoglobinopathies. Rev Med Chil. 2015;143(10):1260-8.

8. Bernal MD, Collazos A, Bonilla RD, Tascón EP. Determination of the prevalence of hemoglobin S, C, D, and $\mathrm{G}$ in neonates from Buenaventura, Colombia. Colomb Médica. 2010;41(2):141-147-147.

9. Restrepo F, Loaiza N, Arrubla M, Cossio S, Ordoñez J. Estudio de la prevalencia de anemia falciforme y otras hemoglobinopatias en población de recién nacidos del Área Metropolitana de Medellín. Memorias taller anual TSH Neonatal. 2010;237-9.

10. Franklin QJ, Compeggie M. Splenic syndrome in sickle cell trait: four case presentations and a review of the literature. Mil Med.1999;164(3):230-3.

11. Goodman J, Hassell K, Irwin D, Witkowski EH, Nuss R. The splenic syndrome in individuals with Sickle Cell Trait. High Alt Med Biol. 2014;15(4):468-71.

12. Bunn HF. Pathogenesis and treatment of sickle cell disease. N Engl J Med. 1997;337(11):762-9.

13. Vekilov PG. Sickle-cell haemoglobin polymerization: is it the primary pathogenic event of sickle-cell anaemia? Br J Haematol. 2007;139(2):173-84.

14. Sheikha A. Splenic syndrome in patients at high altitude with unrecognized sickle cell trait: splenectomy is often unnecessary. Can J Surg J Can Chir.2005;48(5):37781.

15. Norii T, Freeman TH, Alseidi A, Butler WP, Gelford BL. Pressurized flight immediately after splenic infarction in two patients with the sickle cell trait. Aviat Space Environ Med. 2011;82(1):58-60.

16. Cooley JC, Peterson WL, Engel CE, Jernigan JP. Clinical triad of massive splenic infarction, sicklemia trait, and high altitude flying. J Am Med Assoc. 1954;154(2):111-3.

17. Murano T, Fox AD, Anjaria D. Acute splenic syndrome in an African-American male with sickle cell trait on a commercial airplane flight. J Emerg Med.2013;45(5):e161-165.

18. Goldberg NM, Dorman JP, Riley CA, Armbruster EJ. Altitude-related specific infarction in sickle cell trait--case reports of a father and son. West J Med. 1985;143(5):670-2.

19. Thompson AA. Sickle cell trait testing and athletic participation: a solution in search of a problem? Hematology. 2013;2013(1):632-7. 
20. Wand O, Tayer-Shifman OE, Khoury S, Hershko AY. A practical approach to infarction of the spleen as a rare manifestation of multiple common diseases. Ann Med. 2018;50(6):494-500.

21. Cook AL. Splenic infarction in a high-altitude traveler with undiagnosed sickle cell trait. Wilderness Environ Med. 2008;19(4):318-20.

22. López de Guimaraes D, Menacho López J, Villanueva Palacios J, Mosquera Vásquez V. [Splenic infarction at high altitude, Huaraz-Peru (3,100 masl)]. Rev Gastroenterol Peru Organo Of Soc Gastroenterol Peru. 2009;29(2):179-84.

23. Funakoshi H, Takada T, Miyahara M, Tsukamoto T, Noda K, Ohira Y, et al. Sickle cell trait as a cause of splenic infarction while climbing Mt. Fuji. Intern Med Tokyo Jpn. 2010;49(16):1827-9.

24. Pecker LH, Naik RP. The current state of sickle cell trait: implications for reproductive and genetic counseling. Blood. 2018;132(22):2331-8.

25. World Health Organization, Council for International Organizations of Medical Sciences. International ethical guidelines for health-related research involving humans. Geneva: CIOMS; 2017. 